Report

\title{
A population-based study of the impact of delaying radiotherapy after conservative surgery for breast cancer
}

\author{
Nicole Hébert-Croteau ${ }^{1,2}$, Carolyn R. Freeman ${ }^{3}$, Jean Latreille ${ }^{2,4}$, Michèle Rivard ${ }^{5}$, and \\ Jacques Brisson ${ }^{1,6,7}$ \\ ${ }^{1}$ Direction des systèmes de soins et services, Institut national de santé publique du Québec; ${ }^{2}$ Programme \\ d'oncologie, Hôpital Charles LeMoyne, Greenfield Park; ${ }^{3}$ Department of Radiation Oncology, McGill Uni- \\ versity Health Centre, Montréal; ${ }^{4}$ Centre intégré de lutte contre le cancer de la Montérégie (CICM), \\ Greenfield Park; ${ }^{5}$ Département de médecine sociale et préventive, Université de Montréal, Montréal, ${ }^{6}$ Unité de \\ recherche en santé des populations, Hôpital du Saint-Sacrement, Québec; ${ }^{7}$ Département de médecine sociale et \\ préventive, Université Laval, Québec, Québec, Canada
}

Key words: breast neoplasm, combined modality therapy, outcomes research, practice guidelines, radiotherapy, time factors, treatment delay

\section{Summary}

Background. Practice guidelines have set a maximum waiting time to radiation therapy for breast cancer. We evaluated if delaying radiotherapy resulted in worse outcomes in a large cohort of women with nodenegative breast cancer.

Methods. We selected a random sample of cases among women diagnosed with localized breast cancer in five regions of Québec, Canada, between 1988 and 1994. Only women with pathologically $(n=926)$ or clinically $(n=136)$ negative axillary nodes, and stage 1 or 2 disease treated with conservative surgery and radiotherapy were eligible. Information was obtained by chart review, queries to physicians and linkage with administrative databases. Outcomes were estimated by Kaplan-Meier method and Cox proportional hazards analysis. Median follow-up was 7.1 years (range: 0.9-11.8).

Results. Median delay to radiotherapy was 12.4 weeks in those who received chemotherapy and 8.4 weeks in others. Overall survival at 7 years was $85.6 \%$. Local relapse-free and distant disease-free survivals were 77.6 and $76.2 \%$. There was no significant difference in survival according to delay to radiotherapy in crude or multivariate analysis adjusting for several prognostic factors, including systemic treatment. The risk of local failure conditional on survival in women who received radiotherapy more than 12 weeks after surgery was increased (hazard ratio: 1.75, 95\% confidence interval: 1.00, 3.08, $p$-value $=0.052)$.

Conclusions. Although longer waiting time to radiotherapy may compromise local control, it does not influence survival at 7 years when other predictors of outcomes are taken into account. Well controlled studies are needed to confirm and better characterize this relationship.

\section{Introduction}

Radiation therapy following conservative surgery for breast cancer improves local control [1-3] and has been shown to favorably influence survival [4-7]. Additional analysis of the 36 randomized trials included in the Early Breast Cancer Trialists' Collab- orative group meta-analysis that first reported this latter association showed that in recent and large trials, the odds reduction of death from any cause at 10 years associated with radiotherapy was $12.4 \%$ [8]. Alternatives to breast irradiation have been investigated, but it still represents the standard of care, even in women with very small tumors $[9,10]$. 


\section{N Hébert-Croteau et al.}

With increasing demand for radiation therapy as more cases of cancer are diagnosed, due to aging of the population and intensified screening for cancer, and with recent changes in medical practice, access to radiotherapy facilities has been made more difficult in some jurisdictions. A focus of investigation has therefore been to identify shorter, more intensive regimens, having similar efficacy as the standard 25-day fractionation schedule [11], including partial breast irradiation strategies. In addition, the question of whether delaying radiotherapy has or not a detrimental effect on outcomes has become more relevant. Practice guidelines recommend a maximum waiting time to radiotherapy of 8-12 weeks, except in women undergoing chemotherapy [9]. Although theoretical models of breast tumor progression suggest an increase in relapse associated with longer delay to treatment $[12,13]$, the clinical basis of this observation is missing. The vast majority of studies on delay to radiation in women with breast cancer have shown little or no association with outcomes [14, 15]. However, a recent meta-analysis of eight observational studies led to a pooled random effects estimate of the odds ratio (OR) for local recurrence of 1.62 (95\% confidence interval (CI): 1.21-2.16) among women treated between 9 and 16 weeks after surgery compared to those who had radiotherapy earlier [16]. Since no significant heterogeneity was observed across studies, no further adjustment was performed. The association with distant metastasis, as estimated by the pooling of three studies, was not significant. None of the reviewed studies reported on overall survival.

We used data collected on a large cohort of women diagnosed with node-negative breast cancer in Québec, Canada, between 1988 and 1994, and followed until the end of 1999, to evaluate the relationship between delay to radiotherapy and the risk of local or distant recurrence and death. Given the methodological limitations of published studies and evolving patterns of adjuvant systemic treatment in women with early-stage breast cancer, additional study of this issue would be useful.

\section{Materials and methods}

\section{Study population}

The sampling procedure and study population have been described [17]. Briefly, 1727 women newly diagnosed with node-negative breast cancer in 1988-1989, 1991-1992 and 1993-1994 and living in five health regions (Montréal, Laval, Montérégie, Chaudière/Appalaches, Québec) of Québec were identified from the province-wide tumor registry (QTR) and hospital discharge databases, after exclusion of those with multiple primary, multicentric or inflammatory tumors, or lost to follow-up immediately after treatment. The current analysis was restricted to individuals with invasive breast cancer treated by conservative surgery and radiation therapy. Four women with missing information on prescription of chemotherapy were excluded, as well as 24 others with incomplete information on dates of radiotherapy. The final sample included 1062 women. The project was approved by the Commission d'accès à l'information du Québec, the directors of professional services in all hospitals, and research ethics committees.

\section{Data collection}

Information was collected by review of medical charts, including radiation oncology records. This was done twice, first in 1995-1996 to obtain details on disease at diagnosis and treatment of the primary tumor, then 5 years later to document recurrences and deaths. Patients having multiple admissions over time in several hospitals were identified from the QTR longitudinal database and all charts were reviewed. In addition, queries were made to the attending physicians to complete information on prescription of tamoxifen and outcomes of disease. Co-morbidity was estimated from a maximum of 15 secondary diagnoses listed in the hospital discharge summary of the first admission for treatment of breast cancer. This approach has shown better performance in predicting 1-year mortality than medication-based chronic disease scores [18]. Vital status was confirmed by linkage with the mortality database, the QTR and the database on beneficiaries of the Québec universal health insurance system (RAMQ). The RAMQ personal identifier was used for linkage, supplemented by the name at birth, surname, sex and date of birth for solving uncertain matches. RAMQ also identified individuals having moved out of the province before the end of follow-up on December 31, 1999. 
Study variables

Information was collected on the patient, the physician and hospital of primary care, the tumor and details of treatments received within 6 months from diagnosis for chemotherapy and 12 months for radiotherapy and tamoxifen. Charlson's comorbidity index [19] was calculated using the method described by Deyo [20]. Staging used criteria of the 4th edition of the American Joint Committee on Cancer [21]. We collected tumor size at pathology whenever available, otherwise size at mammography or clinical palpation. The highest value of grade assigned to a given tumor was used in the analysis. We combined women with missing value of lymphatic/vascular infiltration with those without infiltration. Delay to radiation was calculated as the interval between the first surgery with curative intent and the first session of radiation therapy. Data were also collected on first recurrences and second primary tumors, including dates of diagnosis and treatment. Because of the lack of central pathology review, we combined local recurrences in the mammary gland, chest wall or surgery scar with ipsilateral second breast primaries in the definition of ipsilateral breast tumor recurrences (IBTR). Second breast primaries were therefore restricted to tumors in the contralateral breast. Regional recurrences were located in ipsilateral axillary nodes, internal mammary chain, infra- or supra-clavicular nodes or soft tissues of the axilla. Distant recurrences were those in the contralateral axillary, internal mammary or infra- or supra-clavicular nodes, as well as in distant sites.

\section{Definition of outcomes}

Two indicators were used to evaluate local control. The first one, local failure-free conditional on survival, included IBTR as event but censored on all other outcomes, including death. The second indicator, local relapse-free survival, counted both IBTR and death as events, and censored on regional or distant recurrence and second primary tumor.

Events included in the computation of distantdisease free survival were regional or distant recurrence, second primary tumor, or death; women with local failure as first event were censored at the date of this occurrence. Finally, overall and breast cancer specific survivals included all-cause or breast cancer specific deaths.

\section{Data analysis}

The associations between delay to radiotherapy and other determinants of outcomes were tested using the Pearson's $\chi^{2}$ test. Survival analysis was done using Kaplan-Meier estimates and Cox proportional hazards models of each end-point defined above. Time under follow-up was computed from the date of pathological diagnosis. It was censored at the last medical consultation in the analysis of recurrences. Women who moved out of the province were censored at the date of moving.

Kaplan-Meier estimates of survival according to delay to radiotherapy were compared by the log-rank test. Survival rates and their 95\% CI at specific years after diagnosis were estimated. Cox proportional hazards models used as main independent variable delay to radiotherapy, and included several prognostic or predictive factors, such as age, co-morbidity, tumor stage, grade, estrogen receptor (ER) status, lymphatic/vascular infiltration, margin status, as well as details of treatment such as dissection of the axilla, tamoxifen, chemotherapy and total dose of radiation to the breast. In all models, the proportionality assumption was verified both graphically and by maximum likelihood estimation using timedependent covariates and goodness-of-fit was assessed by residual analysis. A 5\% level of statistical significance was used and all tests were bilateral.

\section{Results}

\section{Description of the study population}

Table 1 summarizes the main characteristics of the 1062 women under study. The majority were less than 65 years old, had stage 1 disease and no significant co-morbidity. Tumors were grade 1 or 2 in $41.9 \%$, ER-positive in $58.1 \%$, and $8.9 \%$ had some mention of lymphatic or vascular infiltration at pathology. Margin infiltration was reported in $17.8 \%$ of all cases following the last surgery. Absence of regional extension was determined either at pathology $(n=926)$ or clinically $(n=136)$. With regard to systemic treatment, $20.4 \%$ of these individuals received some chemotherapy, and 
190 N Hébert-Croteau et al.

Table 1. Description of the study population

\begin{tabular}{|c|c|c|}
\hline Variable & $n$ & $\%$ \\
\hline \multicolumn{3}{|l|}{ Age, years } \\
\hline$<65$ & 749 & 70.5 \\
\hline$\geq 65$ & 313 & 29.5 \\
\hline \multicolumn{3}{|l|}{ Co-morbidity index } \\
\hline 0 & 990 & 93.2 \\
\hline$\geq 1$ & 70 & 6.6 \\
\hline Missing & 2 & 0.2 \\
\hline \multicolumn{3}{|l|}{ Delay to radiation therapy, weeks } \\
\hline$\leq 8$ & 452 & 42.6 \\
\hline $8-12$ & 319 & 30.0 \\
\hline$>12$ & 291 & 27.4 \\
\hline \multicolumn{3}{|l|}{ Assessment of axillary nodes } \\
\hline Pathology & 926 & 87.2 \\
\hline Clinical & 136 & 12.8 \\
\hline \multicolumn{3}{|l|}{ Tamoxifen } \\
\hline Yes & 574 & 54.0 \\
\hline No & 420 & 39.5 \\
\hline Protocol tamoxifen versus placebo ${ }^{a}$ & 68 & 6.4 \\
\hline \multicolumn{3}{|l|}{ Chemotherapy } \\
\hline Yes & 217 & 20.4 \\
\hline No & 845 & 79.6 \\
\hline \multicolumn{3}{|l|}{ Tumor stage } \\
\hline 1 & 773 & 72.8 \\
\hline 2 & 289 & 27.2 \\
\hline \multicolumn{3}{|l|}{ Grade } \\
\hline $1-2$ & 445 & 41.9 \\
\hline 3 & 286 & 26.9 \\
\hline Missing & 331 & 31.2 \\
\hline \multicolumn{3}{|l|}{ Er status } \\
\hline Positive & 617 & 58.1 \\
\hline Negative & 275 & 25.9 \\
\hline Missing & 170 & 16.0 \\
\hline \multicolumn{3}{|l|}{ Lymphatic/vascular infiltration } \\
\hline Yes & 95 & 8.9 \\
\hline No/missing & 967 & 91.1 \\
\hline \multicolumn{3}{|l|}{ Margin status } \\
\hline Tumor present & 189 & 17.8 \\
\hline Tumor absent & 689 & 64.9 \\
\hline Missing & 184 & 17.3 \\
\hline Total & 1062 & 100 \\
\hline
\end{tabular}

${ }^{\mathrm{a}}$ Includes six women with missing information on tamoxifen.

$54.0 \%$ were prescribed tamoxifen. Overall, $27.4 \%$ of the cohort received radiotherapy more than 12 weeks after breast-conserving surgery. The median interval to radiotherapy was 8.4 weeks (mean: 9.3) among women who did not receive chemotherapy and 12.4 weeks (median 14.0) in those who did; maximum delay was 38 and 50 weeks, respectively.

\section{Factors associated with delay to radiotherapy}

To assess the importance of confounding by indication and the extent by which waiting time to radiotherapy could be influenced by prognosis at baseline, the distribution of delay to radiation according to several prognostic and predictive variables, as well as co-treatment, was evaluated separately among women who received or not chemotherapy (Table 2). Women having more comorbidity were treated more rapidly, whether or not they received chemotherapy, but this relationship was only significant in those who did $\left(\chi^{2}\right.$ $p$-value $=0.035)$. The number of individuals who had a Charlson's index of one or more was however very small (10 and 60 in these two groups).

Women under experimental protocol involving tamoxifen or placebo $(n=62)$ or with missing information on use of tamoxifen $(n=6)$ who did not receive chemotherapy had substantially shorter delay to radiation, as expected, $66 \%$ being treated within 8 weeks, as compared to $44.8 \%$ and $47.1 \%$ of those with or without prescription of tamoxifen who did not participate to clinical research. Otherwise, delay to radiation was not influenced by the fact that a woman had a prescription of tamoxifen, a dissection of the axilla, or by the total dose of radiation delivered to the breast.

No significant association with age, tumor stage, grade, ER status, lymphatic/vascular or margin infiltration was observed among women with known values of these variables, although those with missing information, especially on tumor grade, ER and margins, often experienced different waiting times to radiotherapy. For example, in women who received chemotherapy, $37.5 \%$ of women with grade missing, $56.9 \%$ of those with grade $1 / 2$ and $53.6 \%$ of women with grade 3 tumors were treated more than 12 weeks after surgery. The same trend was observed in individuals who did not receive cytotoxic treatment.

\section{Outcomes according to delay to radiotherapy}

During a median follow-up of 7.1 years (range: $0.9-11.8$ years), 182 women died, 90 of breast 
Table 2. Delay to radiation therapy according to selected variables

\begin{tabular}{|c|c|c|c|c|c|c|c|c|}
\hline \multirow[t]{3}{*}{ Variable } & \multicolumn{4}{|c|}{$\begin{array}{l}\text { Delay in women without chemotherapy, } \\
\text { weeks }(n=845)\end{array}$} & \multicolumn{4}{|c|}{$\begin{array}{l}\text { Delay in women with chemotherapy, } \\
\text { weeks }(n=217)\end{array}$} \\
\hline & $\leq 8$ & $8-12$ & $>12$ & $p$-Value & $\leq 8$ & $8-12$ & $>12$ & $p$-Value \\
\hline & $\%$ & $\%$ & $\%$ & & $\%$ & $\%$ & $\%$ & \\
\hline \multicolumn{9}{|l|}{ Age, years } \\
\hline$<65$ & 44.8 & 33.1 & 22.1 & 0.223 & 25.7 & 23.8 & 50.5 & 0.461 \\
\hline$\geq 65$ & 51.0 & 29.5 & 19.5 & & 20.0 & 13.3 & 66.7 & \\
\hline \multicolumn{9}{|l|}{ Co-morbidity index } \\
\hline 0 & 46.6 & 31.3 & 22.1 & 0.087 & 23.7 & 23.7 & 52.7 & 0.035 \\
\hline$>0$ & 53.3 & 36.7 & 10.0 & & 60.0 & 10.0 & 30.0 & \\
\hline \multicolumn{9}{|l|}{ Dissection of axilla } \\
\hline Yes & 47.5 & 31.7 & 20.8 & 0.654 & 26.5 & 24.0 & 49.5 & 0.160 \\
\hline No & 43.4 & 32.7 & 23.9 & & 14.3 & 14.3 & 71.4 & \\
\hline \multicolumn{9}{|l|}{ Tamoxifen } \\
\hline Yes & 44.8 & 32.1 & 23.1 & $0.715^{\mathrm{a}}$ & 22.3 & 20.2 & 57.4 & $0.231^{\mathrm{a}}$ \\
\hline No & 47.1 & 32.1 & 20.8 & & 28.7 & 25.9 & 45.4 & \\
\hline Protocol tamoxifen vs placebo ${ }^{\mathrm{b}}$ & 66.0 & 28.3 & 5.7 & & 20.0 & 20.0 & 60.0 & \\
\hline \multicolumn{9}{|l|}{ Radiation dose, Gy } \\
\hline$\leq 50$ & 47.2 & 31.8 & 21.0 & 0.710 & 26.5 & 22.5 & 51.0 & 0.341 \\
\hline$>50$ & 42.1 & 31.6 & 26.3 & & 8.3 & 33.3 & 58.3 & \\
\hline \multicolumn{9}{|l|}{ Tumor stage } \\
\hline 1 & 45.9 & 32.0 & 22.1 & 0.394 & 26.1 & 27.0 & 46.8 & 0.270 \\
\hline 2 & 50.8 & 31.1 & 18.0 & & 24.5 & 18.9 & 56.6 & \\
\hline \multicolumn{9}{|l|}{ Grade } \\
\hline $1-2$ & 42.4 & 34.5 & 23.2 & $0.560^{\mathrm{c}}$ & 27.7 & 15.4 & 56.9 & $0.084^{\mathrm{c}}$ \\
\hline 3 & 38.5 & 34.5 & 27.0 & & 17.9 & 28.6 & 53.6 & \\
\hline Missing & 58.1 & 26.8 & 15.1 & & 42.5 & 20.0 & 37.5 & \\
\hline \multicolumn{9}{|l|}{ Er status } \\
\hline Positive & 49.0 & 32.1 & 18.8 & $0.414^{\mathrm{c}}$ & 24.2 & 26.4 & 49.5 & $0.739^{\mathrm{c}}$ \\
\hline Negative & 52.7 & 26.7 & 20.6 & & 24.5 & 21.8 & 53.6 & \\
\hline Missing & 33.8 & 36.4 & 29.9 & & 37.5 & 12.5 & 50.0 & \\
\hline \multicolumn{9}{|l|}{ Lymphatic/vascular infiltration } \\
\hline Present & 42.2 & 40.6 & 17.2 & 0.281 & 32.3 & 25.8 & 41.9 & 0.482 \\
\hline Absent/missing & 47.4 & 31.1 & 21.5 & & 24.2 & 22.6 & 53.2 & \\
\hline \multicolumn{9}{|l|}{ Margin status } \\
\hline Tumor present & 45.3 & 28.1 & 26.6 & $0.446^{\mathrm{c}}$ & 24.0 & 32.0 & 44.0 & $0.188^{\mathrm{c}}$ \\
\hline Tumor absent & 45.4 & 32.4 & 22.2 & & 25.7 & 19.7 & 54.6 & \\
\hline Missing & 53.3 & 33.1 & 13.6 & & 26.7 & 26.7 & 46.7 & \\
\hline Total & 397 & 269 & 179 & 845 & 55 & 50 & 112 & 217 \\
\hline
\end{tabular}

$n$ - number.

${ }^{a}$ Comparison excludes women under protocol or with missing information on tamoxifen.

${ }^{\mathrm{b}}$ Including 6 women with missing information on tamoxifen.

${ }^{\mathrm{c}}$ Comparison excludes women with missing value.

cancer. There were 89 local failures, 35 regional recurrences, 135 distant recurrences, 38 second breast primaries and 52 second primary tumors in the cohort.
Patterns of recurrence did not differ according to waiting time to radiotherapy in crude analysis (Table 3). The probability of being free of local failure at 7 years, conditional on survival, was 
Table 3. Estimates of survival at 7 years according to delay to radiotherapy

\begin{tabular}{|c|c|c|c|c|c|c|c|c|}
\hline & \multicolumn{8}{|c|}{ Outcomes } \\
\hline & $n$ & $\begin{array}{l}\% \text { Local } \\
\text { failure-free } \\
\text { conditional on } \\
\text { survival }(95 \% \mathrm{CI})\end{array}$ & $n$ & $\begin{array}{l}\% \text { Local } \\
\text { relapse-free } \\
\text { survival } \\
(95 \% \mathrm{CI})\end{array}$ & $n$ & $\begin{array}{l}\% \text { Distant } \\
\text { disease-free } \\
\text { survival } \\
(95 \% \mathrm{CI})\end{array}$ & $n$ & $\begin{array}{l}\% \text { Overall } \\
\text { survival } \\
(95 \% \mathrm{CI})\end{array}$ \\
\hline All women & 392 & $90.6(88.5,92.7)$ & 403 & $77.6(74.8,80.4)$ & 395 & $76.2(73.4,79.1)$ & 532 & $85.6(83.4,87.7)$ \\
\hline \multicolumn{9}{|c|}{$\begin{array}{l}\text { Delay to radiotherapy, } \\
\text { weeks }\end{array}$} \\
\hline$\leq 8$ & 223 & $91.6(88.7,94.4)$ & 230 & $77.6(73.5,81.7)$ & 224 & $75.8(71.6,80.1)$ & 293 & $84.7(81.3,88.0)$ \\
\hline $8-12$ & 106 & $91.7(88.0,95.4)$ & 108 & $78.3(73.1,83.5)$ & 108 & $76.4(71.1,81.7)$ & 148 & $85.5(81.3,89.7)$ \\
\hline$>12$ & 63 & $87.1(82.1,92.0)$ & 65 & $76.2(70.4,81.9)$ & 63 & $76.7(71.0,82.3)$ & 91 & $86.8(82.8,90.8)$ \\
\hline \multicolumn{9}{|l|}{ Women with } \\
\hline \multicolumn{9}{|c|}{$\begin{array}{l}\text { Delay to radiotherapy, } \\
\text { weeks }\end{array}$} \\
\hline$\leq 8$ & 32 & $87.7(78.4,97.0)$ & 34 & $75.8(64.3,87.3)$ & 33 & $78.4(67.0,89.8)$ & 40 & $85.2(75.7,94.7)$ \\
\hline $8-12$ & 16 & $97.9(93.9,102.0)$ & 16 & $82.4(71.2,93.6)$ & 15 & $70.6(56.1,85.1)$ & 20 & $83.6(73.2,94.0)$ \\
\hline$>12$ & 36 & $87.9(80.6,95.1)$ & 36 & $77.5(69.0,85.9)$ & 36 & $78.1(69.5,86.7)$ & 50 & $88.1(82.0,94.2)$ \\
\hline $\begin{array}{l}\text { Women withou } \\
\text { chemotherapy }\end{array}$ & \multicolumn{7}{|c|}{ Women without } & $85.4(82.9,87.9)$ \\
\hline \multicolumn{9}{|c|}{$\begin{array}{l}\text { Delay to radiotherapy, } \\
\text { weeks }\end{array}$} \\
\hline$\leq 8$ & 191 & $92.1(89.1,95.1)$ & 196 & $77.8(73.5,82.2)$ & 191 & $75.5(71.0,80.0)$ & 253 & $84.6(81.1,88.2)$ \\
\hline $8-12$ & 90 & $91.6(87.7,95.5)$ & 92 & $77.6(71.8,83.4)$ & 93 & $77.5(71.9,83.2)$ & 128 & $85.9(81.4,90.4)$ \\
\hline$>12$ & 27 & $85.9(78.6,93.2)$ & 29 & $74.6(66.5,82.7)$ & 27 & $75.9(68.6,83.2)$ & 41 & $85.9(80.6,91.3)$ \\
\hline
\end{tabular}

$\mathrm{CI}$ - confidence interval; $n$ - number of women at risk at 7 years.

$90.6 \%$ and varied little with delay to radiotherapy (log-rank test: $1.78, p$-value: 0.411 ), both in women who received or not chemotherapy. Kaplan-Meier estimates of local relapse-free and distant diseasefree survivals were 77.6 and $76.2 \%$. Again, these outcomes were similar across categories of waiting time to radiotherapy (log-rank tests: $0.08, p$-value: 0.959 and 0.35 , $p$-value: 0.840$)$.

For the whole cohort, the 7-year estimate of overall survival was $85.6 \%$ (Table 3 ) and was similar in women who received radiotherapy within 8 weeks, 8-12 weeks, or more than 12 weeks after surgery $(84.7,85.5$ and $86.8 \%, \log$-rank test: 0.66 , p-value: 0.719). Breast cancer specific survival was $92.0 \%$ and displayed the same lack of association with delay in crude analysis $(91.3,93.4$ and $91.4 \%$, log-rank test: $1.84, p$-value: 0.399$)$.

Results of multivariate analyses are summarized in Table 4. In most models, waiting time to radiotherapy was not a significant predictor of outcome after adjustment for other covariates, including systemic treatment received. Hazard ratios (HR) of death from any cause were 0.92 (95\% CI: $0.65,1.30)$ and 0.93 (95\% CI: 0.62, 1.39) in individuals treated 8-12 weeks, and more than 12 weeks after surgery, compared to those treated within 8 weeks. For deaths specific to breast cancer, they were 0.75 (95\% CI: $0.44,1.28)$ and 0.94 (95\% CI: 0.55, 1.61), respectively. Women who started radiotherapy more than 12 weeks after breast-conserving surgery were at increased risk for local failure conditional on survival, and this was of borderline significance (HR: 1.75, 95\% CI: 1.00, 3.08, $p=0.052$ ). This excess risk was mostly concentrated in the subgroup of women who did not receive chemotherapy (HR: 1.91, 95\% CI: 1.00, 3.64, $p=0.049$ ), but was not observed among those who did (HR: 0.97, 95\% CI: 0.31, 3.10, $p=0.962$ ). An interaction term between margin status and delay to radiotherapy was not significant in any model. 
Table 4. Multivariate Cox analysis of delay to radiation therapy and outcomes of breast cancer $(n=1004)$

\begin{tabular}{|c|c|c|c|c|c|c|c|c|}
\hline \multirow{3}{*}{$\begin{array}{l}\text { Delay to } \\
\text { radiotherapy, weeks }\end{array}$} & \multicolumn{8}{|c|}{ Events } \\
\hline & $n$ & $\begin{array}{l}\text { Local } \\
\text { recurrence }\end{array}$ & $n$ & $\begin{array}{l}\text { Local } \\
\text { recurrence or } \\
\text { death }\end{array}$ & $n$ & $\begin{array}{l}\text { Regional/distant re- } \\
\text { currence, second } \\
\text { primary or death }\end{array}$ & $n$ & $\begin{array}{l}\text { Death from } \\
\text { any cause }\end{array}$ \\
\hline & & HR $(95 \%$ CI $)$ & & HR $(95 \%$ CI $)$ & & HR $(95 \%$ CI $)$ & & HR $(95 \%$ CI $)$ \\
\hline$\leq 8$ & 34 & 1.0 & 112 & 1.0 & 124 & 1.0 & 88 & 1.00 \\
\hline $8-12$ & 24 & $1.22(0.71,2.08)$ & 68 & $1.02(0.75,1.38)$ & 74 & $0.96(0.72,1.29)$ & 51 & $0.92(0.65,1.30)$ \\
\hline$>12$ & 27 & $1.75(1.00,3.08)$ & 61 & $1.19(0.85,1.67)$ & 59 & $0.96(0.69,1.35)$ & 40 & $0.93(0.62,1.39)$ \\
\hline
\end{tabular}

$n$ - number of events in category.

$\mathrm{HR}$ - hazard ratio.

NB - estimates are adjusted for age, co-morbidity, dissection of the axilla, dose of radiation to the breast, tumor stage, grade, ER status, lymphatic/vascular infiltration, margin infiltration and systemic adjuvant treatment (none, chemotherapy only, tamoxifen only, both).

\section{Discussion}

In our review [14] of published studies [15, 22-40] on delay in adjuvant radiation treatment and outcomes of breast cancer, we explored the reasons, methodological or others, for inconsistencies in this literature. Four of these investigations [2730] included only patients who did not receive chemotherapy; none suggested a detrimental effect of longer delay to radiotherapy after adjustment for covariates. By contrast, four [22, 34, 35, 40] of 12 studies [15, 22, 31-40] that included patients who did receive chemotherapy and often experienced waiting times to radiotherapy of 6 months or more showed a detrimental effect of longer delay, especially on local control, a result consistent, to some extent, with two $[26,41]$ published randomized studies on sequencing, but not with a third one [42]. It is possible that the impact of delaying radiation therapy would be different in node-negative and positive patients. Whelan et al.'s meta-analysis of trials of radiotherapy in patients with chemotherapy [6] also showed a significant decrease in mortality among patients treated within 6 months of starting chemotherapy (OR for mortality: 0.78, 95\% CI: 0.69, 0.89). Two randomized clinical trials of alternative chemotherapy regimens [31, 32] that provided indirect evidence on the issue of delay to radiation were included in our review, but were negative with respect to this specific hypothesis. Overall, and given the observational nature of the majority of these studies, limitations were identified for several of them, including small sample size, short period of follow-up, lack of proper adjustment for significant prognostic factors, especially margin status which could act as a confounder or a modifier of the effect of delay to radiation, and failure to account for systemic treatment, including tamoxifen. These adjustments are critical, since confounding by indication and selective referral of patients to prompt or late treatment according to their estimated risk of recurrence is plausible. Such selective referral may be more likely in a context where access to care has to be rationalized.

Our series together with the study by Froud et al. [30] which included 1962 patients treated in British Columbia between 1989 and 1993, 80\% of whom were node-negative, represent the largest series of women with node-negative breast cancer investigated to date. Although, as expected, waiting time was longer in patients who received chemotherapy, we did not observe in crude analysis evidence that referral was influenced by determinants of risk of recurrence such as age, tumor grade, ER or margin status, or prescription of tamoxifen in women for whom this information was available. There was a trend for earlier treatment in individuals with more co-morbidity. The reasons why women with missing values about tumor grade, ER receptors or margin infiltration had different patterns of treatment are unclear, apart from the fact that missing information was more common in small tumors during the period our cases were diagnosed. Tendency to treat these women faster or later could therefore exaggerate or attenuate the effect of delay. We did control in our multivariate models for all prognostic and 
predictive factors, including co-morbidity and adjuvant systemic treatment, likely to act as confounders of the delay-outcome relationship.

Like Paszat et al. [43], we used two different indicators to evaluate local control. Differences between them comes from the inclusion of death as either an outcome or a censoring event. Although longer delay did not result in a reduction of local relapse-free survival, there was an increased hazard ratio of local failure conditional on survival with longer time to radiotherapy, of marginal significance in the group with longer delay $(>12$ weeks). Both definitions of local failure should be considered in the assessment of delay to radiotherapy, given the excess mortality, particularly vascular, reported in older trials of radiotherapy, especially after the first 2 years following randomization [5].

Delay to radiation therapy can be calculated from different baselines, including diagnosis, first or last curative surgery. Several published studies have calculated delay from the last surgery, whereas we used date of first surgical intervention. Taking into account, as we did, the time spent with residual disease between the first and last surgery is justified from a biological perspective, whereas calculating delay from the last surgery is more compatible with a rationale of services delivery. However, using the last instead of the first surgery would result in a downward shift in the distribution of our study population according to time to radiation and could attenuate any trend in risk with increasing time to radiotherapy. Thus, differences in the choice of baseline to calculate delay could partly explain variation in study findings.

Huang et al.'s [16] recent meta-analysis also suggests an excess of local failure in women treated later after surgery, but as we previously cautioned [44], this report has limitations. Some important relevant publications were omitted $[23,28,31,32$, 39], whereas in others, some data were excluded from the summary estimates [33, 36, 37]. In addition, research results published only as abstracts were admissible and no meta-regression was performed on the basis of the lack of statistical significance of a test for heterogeneity across studies.

Our study has both strengths and limitations. First, it is population-based and did include approximately half of all new cases of node-negative breast cancer diagnosed in Québec during these years. Second, we were able to adjust for several important covariates, including co-morbidity. Although the information from the medical records may have been incomplete or inaccurate, we tried to upgrade it by direct queries to the attending physicians. This procedure is likely to have minimized misclassification of some variables, especially tamoxifen. In addition, the study population was homogeneous with regard to the extent of disease at diagnosis and the surgical approach used. On the other hand, we had no information on functional status, a factor that could influence both access to care and its outcomes, and follow-up was relatively short given the low risk of recurrence of these cases. Finally, quality of life was not included among the outcomes and could vary substantially with waiting time to treatment.

In conclusion, we observed that delaying radiation therapy following conservative surgery for localized breast cancer was associated with a small marginally significant increase in the risk of local failure conditional on survival, but did not influence other outcomes of treatment, including survival. Indirect evidence provided by randomized clinical trials of chemotherapy should be pooled and more well designed observational studies conducted to clarify this relationship.

\section{Acknowledgements}

We thank Nadia Abdelaziz, Christine Beaulieu, Sylvie Bérubé, Magali Girard, Monika Lessard, Michèle Perron and Brigitte Simard for assistance in data collection and analysis. This project was funded by the Canadian Breast Cancer Research Alliance.

\section{References}

1. Fisher B, Anderson S, Bryant J, Margolese RG, Deutsch M, Fisher ER, Jeong J-H, Wolmark N: Twenty-year follow-up of a randomized trial comparing total mastectomy, lumpectomy, and lumpectomy plus irradiation for the treatment of invasive breast cancer. New Engl J Med 347: 1233-1241, 2002

2. Veronesi U, Cascinelli N, Mariani L, Greco M, Sacozzi R, Luini A, Aguilar M, Marubini E: Twenty-year follow-up of a randomized study comparing breast-conserving surgery with radical mastectomy for early breast cancer. New Engl J Med 347: 1227-1232, 2002 
3. Clark RM, Whelan T, Levine M, Roberts R, Willan A, McCulloch P, Lipa M, Wilkinson RH, Mahoney LJ: Randomized clinical trial of breast irradiation following lumpectomy and axillary dissection for node-negative breast cancer: an update. J Natl Cancer Inst 88: 16591664, 1996

4. Early Breast Cancer Trialists' Collaborative Group: Effects of radiotherapy and surgery in early breast cancer. $\mathrm{N}$ Engl J Med 333: 1444-1455, 1995

5. Early Breast Cancer Trialists' Collaborative Group: Favourable and unfavourable effects on long-term survival of radiotherapy for early breast cancer: an overview of the randomised trials. Lancet 355: 1757-1770, 2000

6. Whelan TJ, Julian J, Wright J, Jadad AR, Levine ML: Does locoregional radiation therapy improve survival in breast cancer? A meta-analysis. J Clin Oncol 18: 1220-1229, 2000

7. Vinh-Hung V, Verschraegen C: Breast-conserving surgery with or without radiotherapy: pooled-analysis for risks of ipsilateral breast tumor recurrence and mortality. J Natl Cancer Inst 96: 115-121, 2004

8. Van de Steene J, Soete G, Storme G: Adjuvant radiotherapy for breast cancer significantly improves overall survival: the missing link. Radiother Oncol 55: 263-272, 2000

9. Whelan T, Olivotto I, Levine M: For the Steering Committee on Clinical Practice Guidelines for the Care and Treatment of Breast Cancer. 6. Breast radiotherapy after breast-conserving surgery (2003 update). CMAJ 168: 437-439, 2003

10. Fisher B, Bryant J, Dignam JJ, Wickerham L, Mamounas EP, Fisher ER, Margolese RG, Nesbitt L, Paik S, Pisansky TM, Wolmark N: Tamoxifen, radiation therapy, or both for prevention of ipsilateral breast tumor recurrence after lumpectomy in women with invasive breast cancer of one centimeter or less. J Clin Oncol 20: 4141-4149, 2002

11. Whelan T, MacKenzie R, Julian J, Levine M, Shelley W, Grimard L, Lada B, Lukka H, Perera F, Fyles A, Laukkanen E, Gulavita S, Benk V, Szechtman B: Randomized trial of breast irradiation schedules after lumpectomy for women with lymph node-negative breast cancer. J Natl Cancer Inst 94: 1143-1150, 2002

12. Mackillop WJ, Bates JHT, O'Sullivan B, Withers HR: The effects of delay in treatment on local control by radiotherapy. Int J Radiat Oncol Biol Phys 34: 243-250, 1996

13. Wyatt RM, Beddoe AH, Dale RG: The effects of delays in radiotherapy treatment on tumour control. Phys Med Biol 48: 139-55, 2003

14. Hébert-Croteau N, Freeman CR, Latreille J, Brisson J: Delay in adjuvant radiation treatment and outcomes of breast cancer - a review. Breast Cancer Res Treat 74: 77-94, 2002

15. Yock TI, Taghian AG, Kachnic LA, Coen JJ, Assaad SI, Powell SN: The effect of delaying radiation therapy for systemic chemotherapy on local-regional control in breast cancer. Breast Cancer Res Treat 84: 161-171, 2004

16. Huang J, Barbera L, Brouwers M, Browman G, Mackillop WJ: Does delay in starting treatment affect the outcomes of radiotherapy? A systematic review. J Clin Oncol 21: 555563,2003

17. Hébert-Croteau N, Brisson J, Latreille J, Gariépy G, Blanchette C, Deschênes L: Time trends in systemic adjuvant treatment for node-negative breast cancer. J Clin Oncol 17: 1458-1464, 1999

18. Schneeweiss S, Seeger JD, Maclure M, Wang PS, Avorn J, Glynn RJ: Performance of comorbidity scores to control for confounding in epidemiologic studies using claim data. Am J Epidemiol 154: 854-864, 2001

19. Charlson ME, Pompei P, Ales KL, MacKenzie CR: A new method of classifying prognostic comorbidity in longitudinal studies: development and validation. J Chron Dis 40: 373-383, 1987

20. Deyo RA, Cherkin DC, Ciol MA: Adapting a clinical comorbidity index for use with ICD-9-CM administrative databases. J Clin Epidemiol 45: 613-619, 1992

21. American Joint Committee on Cancer: Chapter 23 - Breast. In: Philadelphia PA, Lippincott JB (eds) Manual for Staging of Cancer 1992, pp. 145-150

22. Recht A, Come SE, Gelman RS, Goldstein M, Tishler S, Gore SM, Abner AL, Vicini FA, Silver B, Connolly JL, Schnitt SJ, Coleman CN, Harris JR: Integration of conservative surgery, radiotherapy, and chemotherapy for treatment of early-stage, node-positive breast cancer: sequencing, timing, and outcome. J Clin Oncol 9: 1662-1667, 1991

23. Nguyen TD, Naja A, Chaplain G, Mere P: Influence du délai entre la chirurgie et l'irradiation locorégionale sur l'évolution des cancers du sein $\mathrm{N}+$ non métastatiques. Une étude du Groupe des radiothérapeutes de la Fédération nationale des centres de lutte contre le cancer. Bull Cancer Radiother 80: 229-233, 1993

24. Buchholz TA, Hunt KK, Amosson CM, Tucker SL, Strom EA, McNeese MD, Buzdar AU, Singletary SE, Hortobagyi GN: Sequencing of chemotherapy and radiation in lymphnode negative breast cancer. Cancer J Sci Am 5: 159-164, 1999

25. Buzdar AU, Kau SW, Smith TL, Ames F, Singletary E, Strom E, McNeese M, Hortobagyi GN: The order of administration of chemotherapy and radiation and its effect on the local control of operable breast cancer. Cancer 71 : 3680-3684, 1993

26. Recht A, Come SE, Henderson IC, Gelman RS, Silver B, Hayes DF, Shulman LN, Harris JR: The sequencing of chemotherapy and radiation therapy after conservative surgery for early-stage breast cancer. N Engl J Med 334: 1356-1361, 1996

27. Clarke DH, Lê MG, Sarrazin D, Lacombe M-J, Fontaine F, Travagli J-P, Levin-May F, Contesso G, Arriagada R: Analysis of loco-regional relapses in patients with early breast cancers treated by excision and radiotherapy: experience of the Institut Gustave-Roussy. Int J Radiat Oncol Biol Phys 11: 137-145, 1985

28. Nixon AJ, Recht A, Neuberg D, Connolly JL, Schnitt S, Abner A, Harris JR: The relation between the surgeryradiotherapy interval and treatment outcome in patients treated with breast-conserving surgery and radiation therapy without systemic therapy. Int $\mathbf{J}$ Radiat Oncol Biol Phys 30: 17-21, 1994

29. Vujovic O, Perera F, Dar AR, Stitt L, Yu E, Voruganti SM, Truong PT: Does delay in breast irradiation following conservative breast surgery in node-negative breast cancer patients have an impact on risk of recurrence? Int $\mathbf{J}$ Radiat Oncol Biol Phys 40: 868-874, 1998

30. Froud PJ, Mates D, Jackson JSH, Phillips N, Andersen S, Jackson SM, Bryce CJ, Olivotto IA: Effect of time interval 
196 N Hébert-Croteau et al.

between breast-conserving surgery and radiation therapy on ipsilateral breast recurrence. Int J Radiat Oncol Biol Phys 46: 363-372, 2000

31. Fisher B, Brown AM, Dimitrov NV, Poisson R, Redmond C, Margolese R, Bowman D, Wolmark N, Wickerham DL, Kardinal CG, Shibata H, Paterson AHG, Sutherland CM, Robert NJ, Ager PJ, Levy L, Wolter J, Wozniak T, Fisher ER, Deutsch M: Two months of doxorubicin-cyclophosphamide with and without reinduction therapy compared with 6 months of cyclophosphamide, methotrexate, and fluorouracil in positive-node breast cancer patients with tamoxifen-nonresponsive tumors: results from the National Surgical Adjuvant Breast and Bowel Project B-15. J Clin Oncol 8: 1483-1496, 1990

32. Wallgren A, Bernier J, Gelber RD, Goldhirsch A, Roncadin M, Joseph D, Castiglione-Gertsch $\mathrm{M}$ : Timing of radiotherapy and chemotherapy following breast conserving surgery for patients with node-positive breast cancer. Int J Radiat Oncol Biol Phys 35: 649-659, 1996

33. McCormick B, Norton L, Yao TJ, Yahalom J, Petrek JA: The impact of the sequence of radiation and chemotherapy on local control after breast-conserving surgery. Cancer $\mathbf{J}$ Sci Am 2: 39-45, 1996

34. Buchholz TA, Austin-Seymour MM, Moe RE, Ellis GK, Livingston RB, Pelton JG, Griffin TW: Effect of delay in radiation in the combined modality treatment of breast cancer. Int J Radiat Oncol Biol Phys 26: 23-35, 1993

35. Hartsell WF, Recine DC, Griem KL, Murthy AK: Delaying the initiation of intact breast irradiation for patients with lymph node positive breast cancer increases the risk of local recurrence. Cancer 76: 2497-2503, 1995

36. Leonard CE, Wood ME, Zhen B, Rankin J, Waitz DA, Norton L, Howell K, Sedlacek S: Does administration of chemotherapy before radiotherapy in breast cancer patients treated with conservative surgery negatively impact local control? J Clin Oncol 13: 2906-2915, 1995

37. Meek AG, Park TL, Weiss TA, Bethune WA: Effect of delayed radiation therapy on local control in breast conservation therapy. Radiology 200: 615-619, 1996
38. Ampil FL, Burton GV, Li BDL, Mills GM: Radiotherapy with and without chemotherapy after breast conservation surgery for early stage breast cancer: a review of timing. CME J Gynecol Oncol 20: 254-257, 1999

39. Metz JM, Schultz D, Fox K, Matthews A, Glick J, Solin LJ: Analysis of outcomes for high-risk breast cancer based on interval from surgery to postmastectomy radiation therapy. Cancer J 6: 324-330, 2000

40. Slotman BJ, Meyer OWM, Njo KH, Karim ABMF: Importance of timing of radiotherapy in breast conserving treatment for early stage breast cancer. Radiat Oncol 30: 206-212, 1994

41. Calais G, Serin D, Fourquet A, Bosset J, Favre A, Oudinot P, Sunyach M, Tessier E, Bolla M, Cailleux P, Garaud P: Randomized study comparing adjuvant radiotherapy (RT) with concomitant chemotherapy (CT) versus sequential treatment after conservative surgery for patients with stages I and II breast carcinoma. Int J Radiat Oncol Biol Phys 54: 57-58, 2002

42. Rouesse J, Cvitkovic F, De Lalande B, Serin D, Graic Y, Combe M, Leduc B, Lucas V, Demange L, Castera D, Krzisch C, Villet R, Garbay J-R, Nogues C: Concomitant or sequential chemo-radiotherapy (CRT) in operable breast cancer. Final results of a French multicentric phase III study. Breast Cancer Res Treat 76: S160, 2002

43. Paszat LF, Groome PA, Schulze K, Holowaty EJ, Mackillop WJ: A population-based study of the effectiveness of breast conservation for newly diagnosed breast cancer. Int $\mathbf{J}$ Radiat Oncol Biol Phys 46: 345-353, 2000

44. Hébert-Croteau N, Freeman C, Latreille J, Brisson J: Delay to radiation therapy and outcomes of breast cancer. Letter to the editor. J Clin Oncol 22: 1342-1343, 2004

Address for offprints and correspondence: Dr Nicole HébertCroteau, Institut national de santé publique du Québec, 4835, ave. Christophe-Colomb, Montréal, Qc, Canada H2J 3G8; Tel.: +1-514-597-0606, ext. 4419; Fax: +1-514-597-1616; E-mail: Nicole.Hebert-Croteau@Inspq.qc.ca 